[1] Hasday et al. "Nocturnal increase of urinary uric acid: creatinine ration. A biological correlate of sleep-associated hypoxemia." AM Rev Respir Dis 1981, 135:534

[2] Lavie, Lena. "Obstructive sleep apnoea syndrome-an oxidative stress disorder" Sleep Medicine Reviews 2003, 7:35

[3] Roddy et al. "The Association of Gout with Sleep Disorders: a cross-sectional study in primary care."BMC Musculoskeletal Disorders 2013, 14:119

[4] Sahebjani $\mathrm{H}$. "Changes in urinary uric acid excretion in obstructive sleep apean before and after therapy with nasal continuous positive airway pressure." Chest 1998' 113: 1604

[5] Taheri et al. "Short Sleep Duration is Associated with Reduced Leptin, Elevated Ghrelin, and Increased Body Mass Index" PLOS Medicine 2004, $1: 210$

Disclosure of Interests: None declared

DOI: 10.1136/annrheumdis-2020-eular.1369

\section{AB1303-HPR $\quad$ TIME UNTIL DIAGNOSIS IN RHEUMATOLOGICAL PRACTICE: RESULTS FROM A CROSS-SECTIONAL MIDDLE-EUROPEAN COHORT COMPARED TO DATA FROM A SYSTEMATIC LITERATURE REVIEW}

R. Mc-Cutchan ${ }^{1}$, S. Maier ${ }^{1}$, V. Winkler ${ }^{1}$, B. Gruber ${ }^{1}$, M. Schirmer ${ }^{1}$ on behalf of Rheumatology working group of diploma students, Innsbruck. ${ }^{1}$ Medizinische Universität Innsbruck, Innsbruck, Austria

Background: The time from first symptom to diagnosis (= diagnostic delay) is considered as key factor for better outcome in many chronic inflammatory rheumatic diseases, especially for rheumatoid arthritis (RA) and vasculitides like giant cell arteritis (GCA). A longer diagnostic delay may cause pain, reduced functionality, reduced life-quality and increased morbidity, as well as structural damages of the organs linked with higher mortality. This retrospective study assessed the diagnostic delay in consecutive Middle-European outpatients and compared results with those of a systematic literature review (SLR).

Objectives: To compare disease-specific diagnostic delays of consecutive rheumatic patients with international data from a systematic literature review.

Methods: Charts of a single-centre cohort with consecutively recruited patients were retrospectively reviewed for patients' and diseases' characteristics at a Middle-European university outpatient clinic for rheumatology. A SLR was performed according to PRISMA guidelines.

Results: The average mean \pm SD time from first symptom to established diagnosis was $7.9 \pm 11.7(0.02-56.7)$ years. Spondyloarthritis patients showed the longest diagnostic delay with $13.1 \pm 14.2(0.1-56.7)$ years, whereas polymyalgia rheumatica-patients had the shortest diagnostic delay with $1.5 \pm 0.4$ (0.3-18.0) months. In the SLR, most data for diagnostic delays are comparable to the Innsbruck cohort, but the diagnostic delay for psoriatic arthritis in Innsbruck is longer than in the Danish DANBIO registry $(p<0.001)$. Independent risk factors for prolonged diagnostic delays could not be identified.

Conclusion: For this Middle-European area, initiatives are justified especially to shorten diagnostic delays of SpA and PsA.

References:

[1] O'Dell JR. Treating rheumatoid arthritis early: A window of opportunity? Arthritis Rheum. 2002;46:283-5.

[2] Seo MR, Baek HL, Yoon HH, Ryu HJ, Choi HJ, Baek HJ, et al. Delayed diagnosis is linked to worse outcomes and unfavourable treatment responses in patients with axial spondyloarthritis. Clin Rheumatol. 2015;34:1397-405.

[3] Diagnostic delay of more than 6 months contributes to poor radiographic and functional outcome in psoriatic arthritis. Ann Rheum Dis. 2015;74:1045-50.

[4] Dejaco C, Brouwer E, Mason JC, Buttgereit F, Matteson EL, Dasgupta B. Giant cell arteritis and polymyalgia rheumatica: current challenges and opportunities. Nat Rev Rheumatol. Nature Publishing Group; 2017;13:578-92.

Acknowledgments: We acknowledge and thank all patients who could be recruited to the SolutionX project. Ethical vote was obtained by the local ethics committee of the Medical University of Innsbruck (AN2017-0041 370/4.18).

Disclosure of Interests: Rick Mc-Cutchan: None declared, Sarah Maier: None declared, Valentin Winkler: None declared, Bernhard Gruber: None declared, Michael Schirmer Grant/research support from: total <3000.- $€$, Speakers bureau: total $<3000$. $€$

DOI: 10.1136/annrheumdis-2020-eular.3724

\section{AB1304-HPR KNOWLEDGE OF HIGH SCHOOL STUDENTS ABOUT RHEUMATIC DISEASES: EFFECT OF AN EDUCATIONAL SESSION JOINTLY PROVIDED BY PORTUGUESE EULAR ASSOCIATIONS}

G. Pimentel ${ }^{1}$, A. Marques ${ }^{2,3}$, R. Ferreira ${ }^{2,3}$, E. Mateus ${ }^{4}$, A. Pais ${ }^{5} .{ }^{1} \mathrm{CHUC}$, Internal Medicine, Coimbra, Portugal; ${ }^{2} \mathrm{CHUC}$, Rheumatology, Coimbra, Portugal; ${ }^{3}$ UICISA:E, ESEnfc, Coimbra, Portugal; ${ }^{4}$ Portuguese League Against
Rheumatic Diseases, Lisboa, Portugal; ${ }^{5}$ Portuguese Association of Childhood with Arthritis and Rheumatism, Lisboa, Portugal

Background: International studies have shown that the awareness and knowledge of the general population about rheumatic and musculoskeletal diseases (RMDs) is poor. This is even lower in the young population, which are also affected by these disease but do not have as much awareness campaigns as adult community. Their professors and primary health care professionals may also play here also a key role, promoting early detection of signs and interpretations of symptoms, thus avoiding late health care referrals and diagnosis. (Vlieland, 2016).

Objectives: To assess the knowledge of high school Portuguese students about the RMDs and raise awareness for RMDs in young people, their professors, vig ilants, and primary care nurses, within the school environment.

Methods: A 1-hour educational session about RMDs was planned (with the inputs from members of the Portuguese EULAR Associations) and performed during school activities. The educational session started with a knowledge questionnaire about RMDs in a paper sheet (9 questions; Graph 1), repeated in the end. An interactive session, using slides, interactive questions (Sli.do®), and practical demonstrations to simulate RMD symptoms (e.g. stiffness and functional limitations) was then lead by a rheumatology nurse, with the testimony from a young patient representative. A primary care nurse assisted in order to be engaged and promote future sessions ("autonomously"). Change in knowledge was assessed with Wilcoxon-test and awareness was documented with "word clouds" (using Sli.do®).

Results: A total of 75 students participated in four sessions (mode=16 years). Half of students $(52 \%)$ had never heard about RMDs. Knowledge increased significantly in all questions ( $p<0.001$; Graph 1). Figures 1 and 2 document the most common words representing what defines a RMD and what are the main symptoms, respectively.

Graph 1. Change in the percentage of correct answers before and after na educational session $(n=75$ ) (all $p<0.001$ )

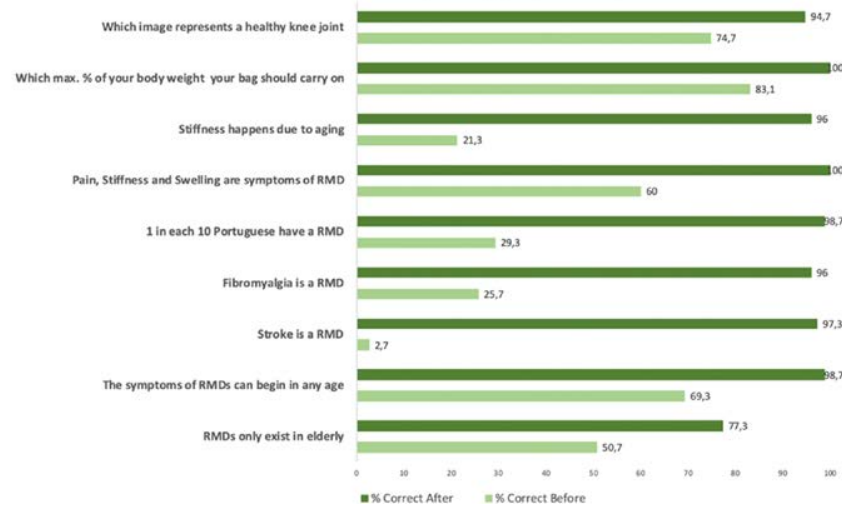

Figure 1. "One to two words" to define "Rheumatic diseases" by college students $(n=75)$ after an educational session

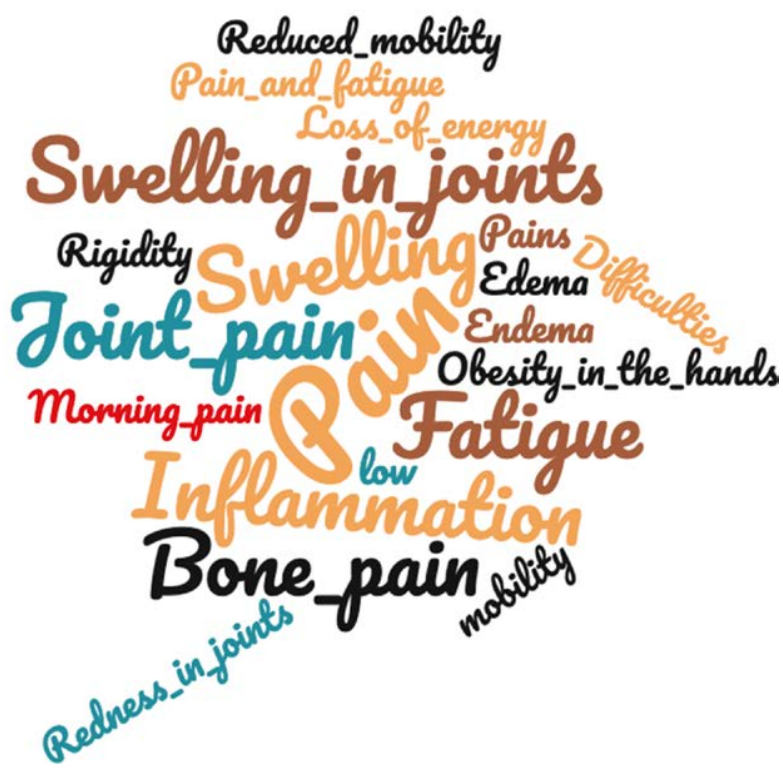

